\title{
Microstructure and Hardness Profiles of Bifocal Laser-Welded DP-HSLA Steel Overlap Joints
}

\author{
A. Grajcar, P. Matter, S. Stano, Z. Wilk, and M. Różański
}

\author{
(Submitted October 4, 2016; in revised form January 19, 2017; published online March 15, 2017)
}

\begin{abstract}
The article presents results related to the bifocal laser welding of overlap joints made of HSLA and DP high-strength steels. The joints were made using a disk laser and a head enabling the 50-50\% distribution of laser power. The effects of the laser welding rates and the distance between laser spots on morphological features and hardness profiles were analyzed. It was established that the positioning of beams at angles of $0^{\circ}$ or $90^{\circ}$ determined the hardness of the individual zones of the joints, without causing significant differences in microstructures of the steels. Microstructural features were inspected using scanning electron microscopy. Both steels revealed primarily martensitic-bainitic microstructures in the fusion zone and in the heataffected zone. Mixed multiphase microstructures were revealed in the inter-critical heat-affected zone of the joint. The research involved the determination of parameters making it possible to reduce the hardness of joints and prevent the formation of the soft zone in the dual-phase steel.
\end{abstract}

Keywords bifocal laser welding, dual-phase steel, hardness profile, high-strength steel, metallurgical weldability, microstructure

\section{Introduction}

The constant development of the automotive industry entails the necessity of reducing the consumption of raw materials during the production and operation of vehicles. This development also involves extensive works focused on improving vehicle safety (Ref 1-4). Basing on these assumptions, increasing amounts of high-strength low-alloyed (HSLA) and complex-phase steels (e.g., dual-phase, complex-phase, transformation-induced plasticity) are implemented in car bodies (Ref 5,6$)$. The use of high-strength steels enables the car structures production of thinner sheets. This results in reducing the total weight of vehicles and decreasing fuel consumption $(\operatorname{Ref} 2,4,7)$. The appropriate selection of both chemical and phase compositions of modern steels makes it possible to forecast the behavior of car bodies during collisions, thus predicting passenger safety. The chemical composition of HSLA steels is based on $\mathrm{Ti}, \mathrm{Nb}$ and $\mathrm{V}$ microadditions, which form carbides and nitrides in ferrite (Ref 8-10). In turn, an important feature of dual-phase steels (DP) is the combination of martensite and ferrite proportions so that high strengthening potential and significant elongation is provided (Ref 11-14).

A. Grajcar, P. Matter, and Z. Wilk, Faculty of Mechanical Engineering, Silesian University of Technology, 18a Konarskiego Street, 44-100 Gliwice, Poland; and S. Stano and M. Różański, Institute of Welding, 16-18 Bl. Czesława Street, 44-100 Gliwice, Poland. Contact e-mail: adam.grajcar@polsl.pl.
To obtain optimal economical results, it is necessary to select both appropriate methods and parameters of elements joining (Ref 15-18). Therefore, the focus is to achieve maximum possible joining rates while obtaining high mechanical properties of joints and their resistance against brittle cracking. Laser welding has been widely used in the automotive industry because of high process stability, easy process automation, low energy losses and high welding rates. In order to improve the quality of welded joints, welding processes can involve the use of a dual laser beam generated by two lasers or formed by splitting a single laser beam. The use of bifocal beams enables more precise control of joining processes, directly affecting microstructures of joints and their mechanical properties (Ref 2,16).

The dual-beam laser welding is a relatively new method of joining. There are some works on the use of the dual-beam laser welding in case of aluminum and titanium alloys or zinc-coated steel sheet (Ref 19-21). The use of dual-beam laser welding increases the amount of heat inputted to material leading to slower cooling rates. Moreover, this effect can be obtained after applying an increased distance between beams. Capello et al. (Ref 22) reported that it may positively affect the microstructure and hardness reduction in welds.

The field of dual-spot laser welding as well as dissimilar welding of HSLA and multiphase steels is relatively new. Results published recently by Rossini el al. (Ref 23), Zhu and Xuan (Ref 24) and Yuce et al. (Ref 25) are very promising and may introduce new more effective and more efficient techniques of joining metal parts. Many elements in the automotive industry are connected using overlap joints. The growing importance of dual-phase steels in the automotive industry has inspired this study that focused on the assessment of the microstructure and hardness profiles of HSLA and DP steels overlap joints. Therefore, the main idea and novelty of the study is to investigate the effects of various bifocal welding parameters (such as beams positioning, welding rate and the distance between laser spots) on microstructure and resulting hardness profiles of HSLA-DP steel overlap joints. 


\section{Materials and Methods}

\subsection{Materials}

Materials used in the tests were two steel sheets used in the production of lightweight safety-improved car elements, i.e., Docol H420LA and Docol 800DP. During welding tests, a 1mm-thick sheet made of steel HSLA was placed on a $0.8-\mathrm{mm}$ thick DP steel sheet. The chemical compositions of the steels according to the producer catalog (SSAB) are presented in Table 1. Considering HSLA steels, the low carbon content and high content of $\mathrm{Mn}, \mathrm{Nb}$ and $\mathrm{Ti}$ are responsible for the formation of a primarily ferritic structure with a little pearlite fraction. The chemical compositions of the two tested steels are compared schematically in Fig. 1. Due to the slight degree of work strengthening during plastic deformation (up to approximately $100 \mathrm{MPa}$ ), HSLA steels are designated with the minimum value of YS, which for H420LA is restricted within the range of $420 \mathrm{MPa}$ to $520 \mathrm{MPa}$.

In turn, dual-phase steels are designated with the minimum value of UTS because of a significant rate of work hardening during deformation (an increase in stress of approximately $300 \mathrm{MPa}$ ). Dual-phase steels are characterized by a higher carbon content (than HSLA steels). It is utilized during heat treatment when the formation of hard martensite takes place in a soft ferrite matrix. The increase in the ultimate tensile strength of DP steels up to approximately $800 \mathrm{MPa}-900 \mathrm{MPa}$ results in the reduction in uniform elongation A80 from 17\% (HSLA) to $10 \%$ (DP). The hardness values measured before the welding tests are $194 \pm 8$ HV5 (HSLA) and $263 \pm 11$ HV5 (DP).

\subsection{Bifocal Laser Welding}

The welding tests of the overlap joints were performed using an automated rig equipped with a TruDisk 12002 laser disk and a Trumph D70 welding head. This head enables to split the beam into two. Variable and constant parameters used in the tests are presented in Table 2, whereas detailed data concerning parameters used when welding individual specimens are presented in Table 3. The positioning of beams at an angle of $\alpha=0^{\circ}$ designates the tandem mode (i.e., beams positioned one after the other, in accordance with the direction of welding), whereas the positioning of beams at an angle of $\alpha=90^{\circ}$ means that the beams are positioned in a line perpendicular to the direction of welding, as an example shown in Fig. 2. The variable parameters also include a focal length $(f)$, where a given value refers to the distance from the upper surface of the upper sheet. The penetration of the focal length in the welded material is provided in negative values.

\subsection{Microstructure Tests}

Before the microscopic observation, the joints were selected on the basis of a visual assessment. Specimens containing significant welding imperfections and those made during unstable welding processes were rejected. The structural tests were preceded by standard metallographic preparations including grinding, polishing and etching in a $2 \%$ Nital solution. The macro- and microscopic analyses were performed using a Zeiss AxioObserver.Z1 m light microscope at $\times 50, \times 100, \times 500$ and $\times 1000$ magnifications. The morphological details of structural constituents in various areas of the joints were revealed using a Zeiss Supra 25 scanning electron microscope (SEM). The

Table 1 Chemical compositions of the welded steel sheets and the carbon equivalents according to the producer catalog (Ref 26)

\begin{tabular}{|c|c|c|c|c|c|c|c|c|c|c|}
\hline Grade & $\mathrm{C} \max ., \%$ & Si max., \% & Mn max., \% & Al min., \% & Nb max., \% & Ti max., \% & P max., \% & $\mathrm{S} \max ., \%$ & Fe max., \% & $\mathrm{C}_{\mathrm{e}}, \%$ \\
\hline Docol H4 & 0.10 & 0.50 & 1.60 & 0.015 & 0.090 & 0.15 & 0.025 & 0.025 & Bal. & 0.20 \\
\hline Docol 800DP & 0.14 & 0.20 & 1.50 & 0.015 & 0.015 & $\ldots$ & 0.010 & 0.002 & Bal. & 0.22 \\
\hline
\end{tabular}

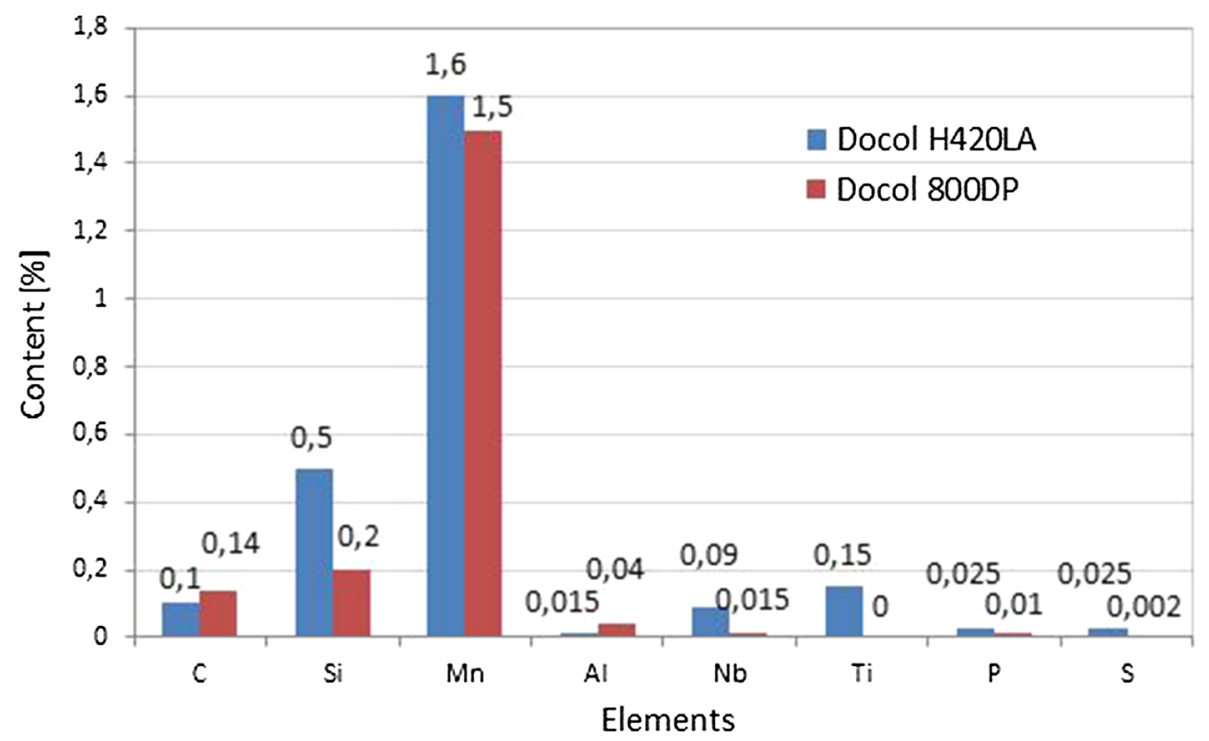

Fig. 1 Weight contents of alloying elements in the sheet steels 
Laser power $6 \mathrm{~kW}$

Equal beam power distribution

Diameter of the spot in the focus $0.6 \mathrm{~mm}$

Identical focal length of both beams
Linear rate, $v$

Positioning of the beams in relation to the direction of welding, $\alpha$ Distance between the beams, $d$

Focal length in relation to the upper surface of sheet, $f$

Table 3 Variable welding parameters

\begin{tabular}{lcccc}
\hline Specimen no. & $\boldsymbol{v}, \mathbf{m} / \mathbf{m i n}$ & $\boldsymbol{\alpha} \boldsymbol{~}^{\circ}$ & $\boldsymbol{d}, \mathbf{m m}$ & $\boldsymbol{f}, \mathbf{m m}$ \\
\hline 1 & 6.0 & 90 & 0.6 & -5 \\
2 & 8.0 & 90 & 0.6 & -5 \\
3 & 7.0 & 90 & 0.6 & 1.0 \\
4 & 8.5 & 0 & 1.0 & 0 \\
5 & 9.5 & 0 & 0 \\
\hline
\end{tabular}

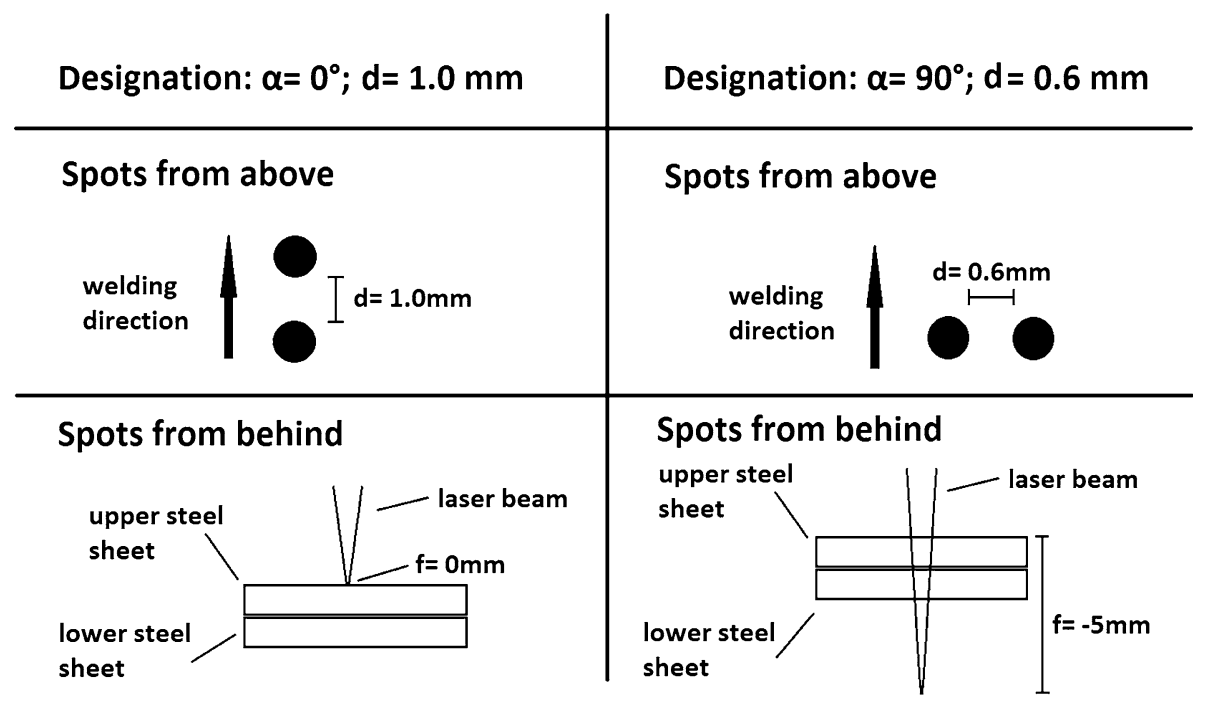

Fig. 2 A schematic illustration of the exemplary beams positioning

accelerating voltage amounted to $25 \mathrm{kV}(\times 5 \mathrm{k}, \times 10 \mathrm{k}$ and $\times 20 \mathrm{k}$ magnification).

\subsection{Hardness Tests}

The joints were subjected to rigorous hardness tests. They consisted of measurements of the specimens obtained at the highest welding rates. The measurements were taken using a Vickers hardness tester and a load of 49 N. As is shown in Fig. 3, the cross sections of the joints contained 15 measurement points located in each sheet, at the half of their thicknesses. Due to the narrow width of the heat-affected zone (HAZ), points 4-6 and 1012 did not lie at the half of sheet thicknesses.

\section{Results and Discussion}

\subsection{Base Material}

The geometrical parameters of welds made using various laser welding parameters presented in Table 3 were analyzed in detail by Stano et al. (Ref 27). The use of the split laser beam changed the process of laser welding when compared to the conventional process performed using the single-spot beam. It was established that distances between two laser beam focuses as well as the positions of beams and welding rates affected the penetration shape and the width of individual microstructural zones. This research involved detailed microstructural tests performed for selected joints.

Both light and scanning electron microscopic observations made it possible to easily differentiate between the two materials used in the tests. The microstructure of the HSLA steel consisted mainly of ferrite (Fig. 4), partially surrounded by pearlite. In turn, the DP steel contained the high content of martensite (approximately 45\%) together with a surrounding ferrite (Fig. 5).

The sizes of ferrite grains in the H420LA steel were restricted within the range of $4 \mu \mathrm{m}$ to $10 \mu \mathrm{m}$. This was due to the high contents of $\mathrm{Ti}$ and $\mathrm{Nb}$, which, in the form of carbonitrides, impeded the growth of austenite grains (Ref 28). In steel $800 \mathrm{DP}$, grains were slightly larger $(4-13 \mu \mathrm{m})$ and the 


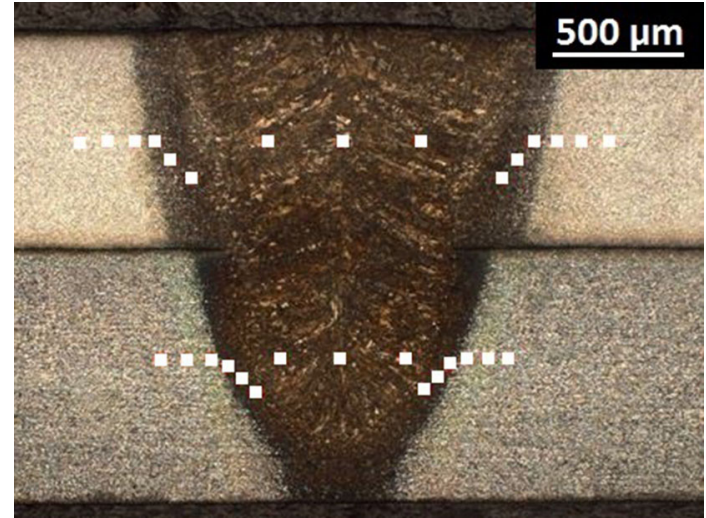

Fig. 3 Measurement points applied during hardness tests
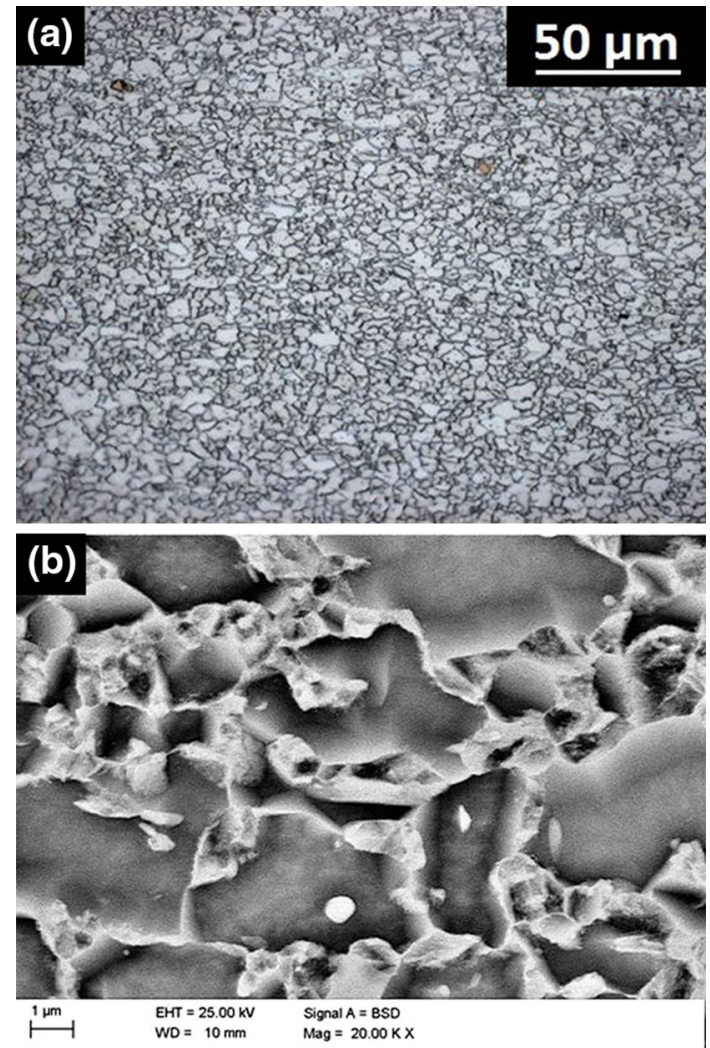

Fig. 4 Ferritic-pearlitic microstructure of steel H420LA observed using: (a) light microscopy; (b) scanning electron microscopy

structure had a slightly band-like form after rolling. The similar microstructure of steel DP 600 and DP 980 was identified by Farabi et al. (Ref 7).

\subsection{Fusion Zone}

Because of the high cooling rate following the passage of a laser beam, the fusion zone structure was mainly composed of lath martensite (Fig. 6). These observations were confirmed by micrographs obtained using SEM for various laser welding rates (Fig. 7). In addition to martensite, the microstructure contained martensite-austenite blocks (M-A) visible at greater magnifications (Fig. 8). Figure 8 also reveals the prior austenite boundaries. Farabi et al. (Ref 7), when examining the DP 600
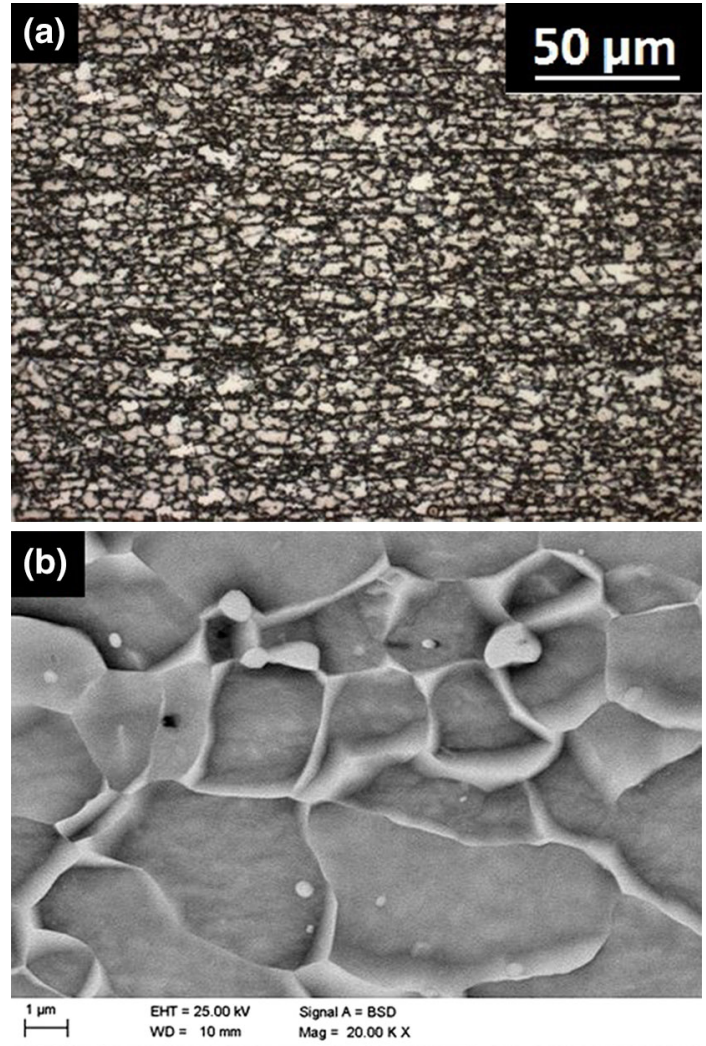

Fig. 5 Ferritic-martensitic microstructure of steel 800DP observed using: (a) light microscopy; (b) scanning electron microscopy

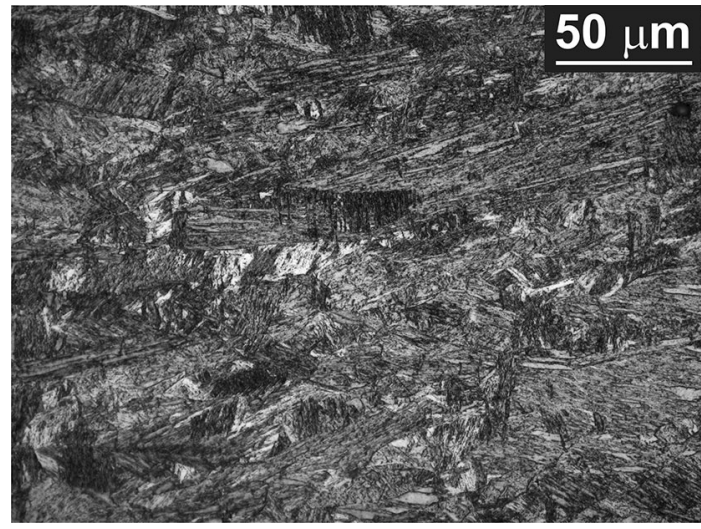

Fig. 6 Fusion zone at $\times 500$ magnification registered for the following welding parameters: $v=9.5 \mathrm{~m} / \mathrm{min}, \alpha=0^{\circ}, d=1.0 \mathrm{~mm}$, $f=0 \mathrm{~mm}$

steel using similar linear energy, also revealed the presence of lath martensite with a slight bainite content. Similar results were also obtained by Xia et al. (Ref 2) in the case of steel DP980 welded using a higher welding rate and a smaller diode light spot in the focusing point.

As the compared microstructures were obtained by different parameters, it may be seen that the microstructure components in Fig. 7(a) are smaller and the average length of martensite laths does not exceed $10 \mu \mathrm{m}$. In addition, in some areas there occur parallel martensite laths separated by packets of smaller laths at the angle of app. $90^{\circ}$. The number of martensite- 

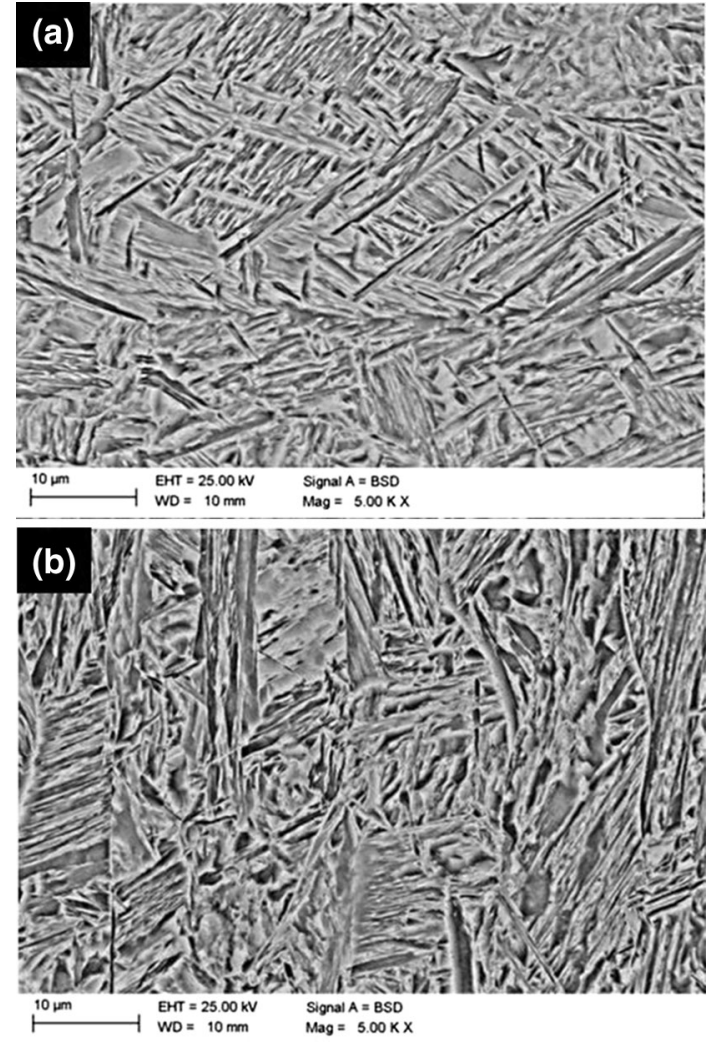

Fig. 7 Fusion zone at $\times 5000$ magnification for different welding parameters: (a) $v=6.0 \mathrm{~m} / \mathrm{min}, \alpha=90^{\circ}, d=0.6 \mathrm{~mm}, f=-5 \mathrm{~mm}$; (b) $v=9.5 \mathrm{~m} / \mathrm{min}, \alpha=0^{\circ}, d=1.0 \mathrm{~mm}, f=0 \mathrm{~mm}$

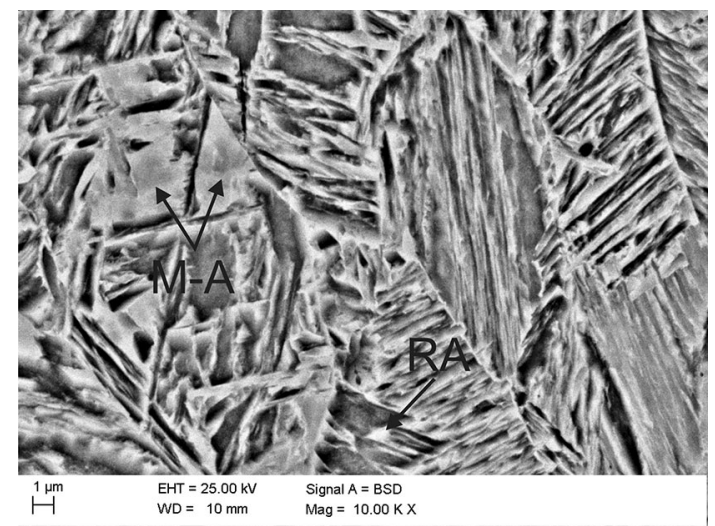

Fig. 8 Fusion zone at $\times 10 \mathrm{k}$ magnification; welding parameters: $v=9.5 \mathrm{~m} / \mathrm{min}, \alpha=0^{\circ}, d=1.0 \mathrm{~mm}, f=0 \mathrm{~mm}$; M-A - martensiteaustenite blocks

austenite (M-A) blocks is similar in both cases. Although in the first case, the welding rate was about $50 \%$ slower, in the latter one the beam was followed by another and both of them were focused on the upper surface of steel sheet. This entails the higher heat exposure, thus allowing grains to grow. Considering welding with $90^{\circ}$ positioning and focusing beams below a steel sheet surface, the heat energy was dispersed over a larger area. That is why the material cooled down faster and the obtained martensite laths are shorter. Yuce et al. (Ref 25) welded HSLA and MS steels at a linear energy only 9\% smaller and their FZ

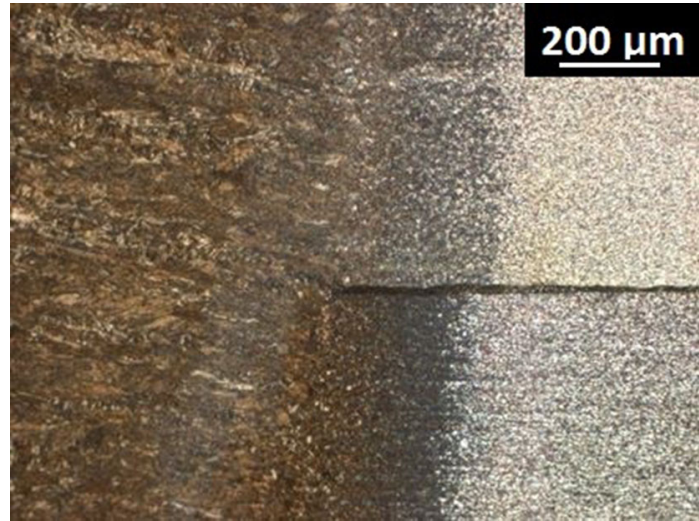

Fig. 9 Weld structure at $\times 100$ magnification

microstructure consisted of predominantly martensite and bainite.

\subsection{Heat-Affected Zone}

Figure 9 presents the joint microstructure composed of (from the left) the fusion zone, the HAZ, the inter-critical HAZ and the base material. During welding, in the fusion zone, the materials of both sheets mix and crystallise forming a homogenous, primarily martensitic, microstructure. In turn, in particular HAZ subzones, depending on steel grades, some changes take place, thus triggering formation of various structures. The HAZ subzones for both steel grades are depicted in Fig. 10. The coarse-grained HAZ (CG), finegrained HAZ (FG), inter-critical HAZ (IC) and in case of the DP steel subcritical HAZ (SC) and partially molten zone (PMZ) can be identified. The microstructure of the FG-HAZ and CGHAZ zone consists of martensite and bainite. The amounts of mentioned phases can vary according to a steel grade. Yuce et al. (Ref 25) reported that the higher CE equivalent value determines a higher martensite amount. For this reason, the HAZ of DP steel contains more martensite than it may be observed in the HSLA steel.

By contrast to the DP steel, the FG-HAZ of HSLA steel is narrower than its CG-HAZ. It is related to the higher amount of generated thermal energy in the upper sheet. Next, the heat is transferred due to thermal conductivity and by convection of the liquid metal to the lower sheet via the interphase between these sheets. Moreover, the upper sheet is directly irradiated by the laser beam. Post-weld heat treatment (PWHT) carried out by Zhu and Xuan (Ref 29) resulted in obtaining other HAZ microstructure. As distinct from the present work, bainite and $\delta$-ferrite were formed close to the fusion line. Moreover, they identified (Ref 30) the occurrence of ferrite in the weld metal, near the fusion line, although fusion zone mainly consisted of strip-like bainites and martensite. It shows that the microstructure of the HAZ depends strongly on a chemical composition and welding parameters.

In the IC-HAZ, newly formed martensite islands may be found due to the lower temperature (in the range between $A_{1}$ and $A_{3}$ ). The content of ferrite grains increases gradually in HSLA steel, unlike in DP, where the microstructure radiply changes from FG-HAZ to IC-HAZ (Fig. 10). The existence of subcritical HAZ (SC) may be also observed in Fig. 10 as a region between BM and IC-HAZ. This zone consists of ferrite and tempered martensite (Ref 11, 23). 

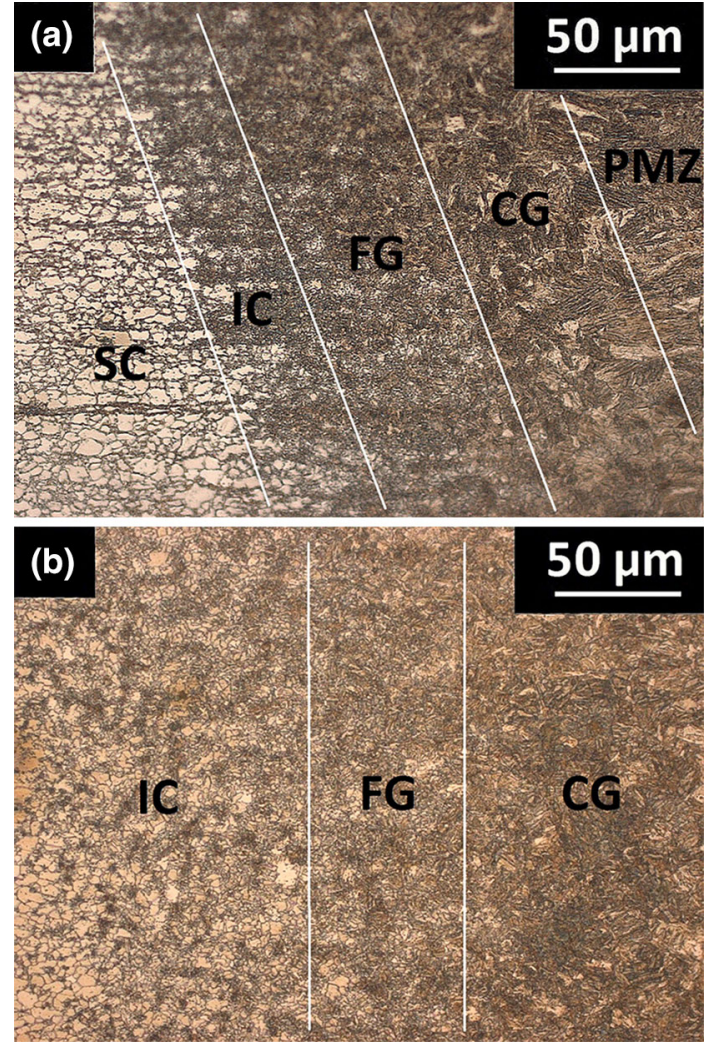

Fig. 10 Subzones of the HAZ at $\times 500$ magnification: (a) DP steel; (b) HSLA steel; subcritical HAZ (SC), inter-critical HAZ (IC), finegrained HAZ (FG), coarse-grained HAZ (CG), partially molten zone (PMZ); welding parameters: $v=10 \mathrm{~m} / \mathrm{min}, \alpha=0^{\circ}, d=1.0 \mathrm{~mm}$, $f=0 \mathrm{~mm}$

Generally, the HAZ of DP steel was characterized by the fine-grained microstructure containing the mixture of martensite, bainite and retained austenite (Fig. 11a). Grain boundaries formed during austenitisation were also clearly visible (Fig. 12). Consequently, the H420LA steel contained mainly the mixture of martensite and bainite (Fig. 11b) and films of retained austenite (Fig. 13). The HAZ width decreased along with increasing welding rates, which was directly related to a decrease in linear energy, also observed by Algahtani et al. (Ref 1) using a lower laser power. They reported that the decrease in the laser power from $2.5 \mathrm{~kW}$ to $1.5 \mathrm{~kW}$ was accompanied by greater structural refinement and the higher content of structural constituents typical for high cooling rates.

\subsection{Transition Zone}

The inter-critical HAZ of DP steel contained a microstructure which had undergone partial austenitisation and re-cooling, resulting in the reduction in the average grain size by half. Changes were also noticed as regards the geometry of ferrite grains which became irregular (Fig. 14). In addition, in contrast to the microstructure of the base material, the transition zone microstructure contained grains of retained austenite. This structural constituent can be identified as bright blocky grains decorating ferrite grain boundaries (Ref 10).

In the HSLA steel, most of the structural constituents underwent further refinement. Because of the lower content of alloying elements, in addition to ferrite, the microstructure
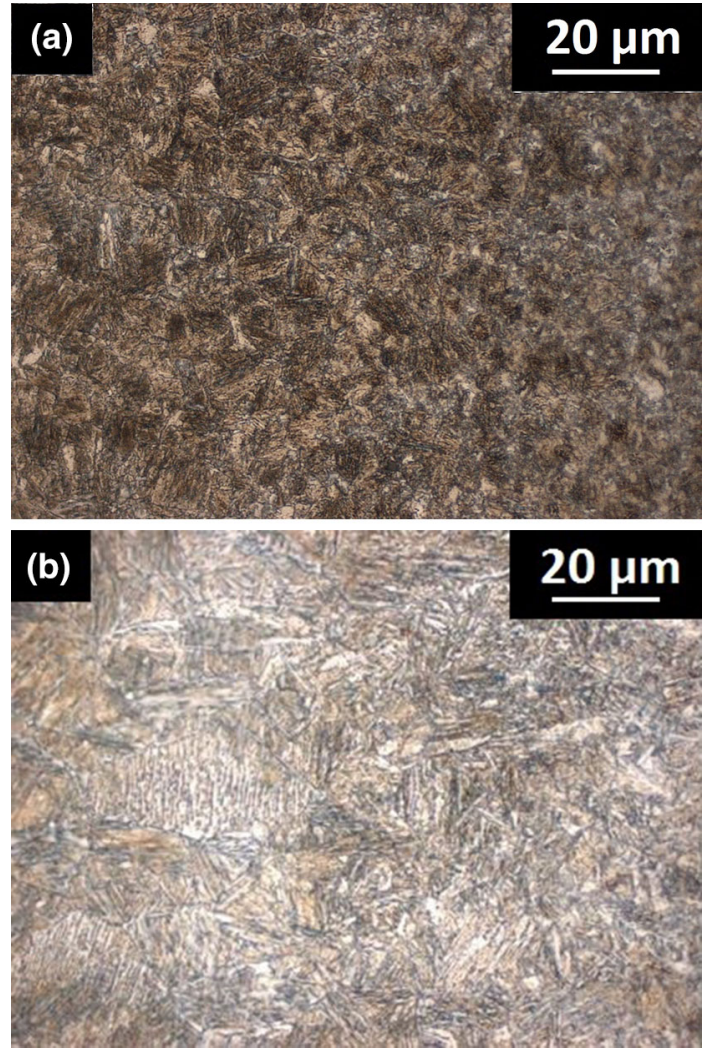

Fig. 11 HAZ microstructure at magnification $\times 1000$ : (a) DP steel-FG-HAZ; (b) HSLA steel-the transition between CG-HAZ (from the left) and FG-HAZ (from the right); welding parameters: $v=7.0 \mathrm{~m} / \mathrm{min}, \alpha=90^{\circ}, d=0.6 \mathrm{~mm}, f=-5 \mathrm{~mm}$

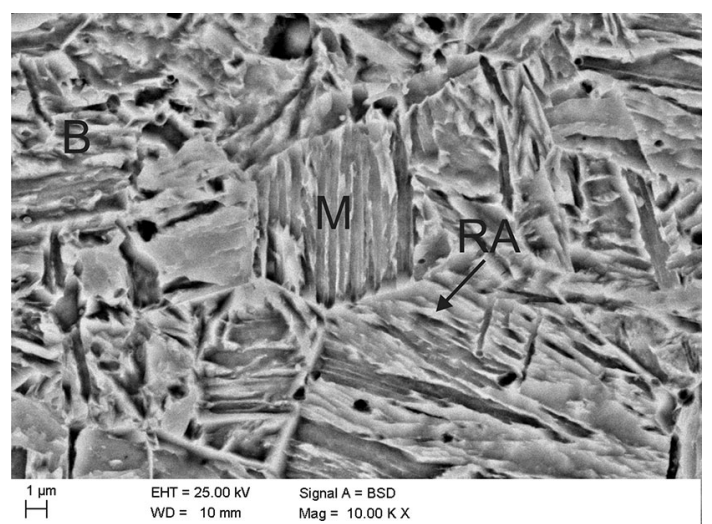

Fig. 12 HAZ microstructure in steel DP for the following welding parameters: $v=8.5 \mathrm{~m} / \mathrm{min}, \quad \alpha=0^{\circ}, \quad d=1.0 \mathrm{~mm}, \quad f=0 \mathrm{~mm}$; $\mathrm{M}$ - martensite, $\mathrm{B}$ - bainite, RA—retained austenite

contained martensitic-bainitic regions and significantly less retained austenite (Fig. 15).

\subsection{Hardness Profiles}

The hardness measurement results concerning the twin-spot laser beam-welded joints obtained for both cases of the beams positioning were compared to the results of the previous tests. In those tests, welding was performed using the single-spot laser beam (Ref 27). Single-spot beam welding was performed at a welding rate of $11-12 \mathrm{~m} / \mathrm{min}$; the maximum hardness of the 


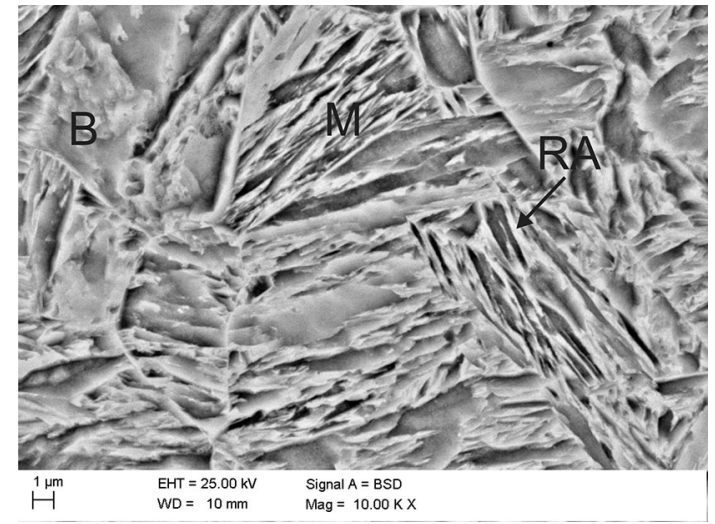

Fig. 13 HAZ microstructure in steel HSLA for the following welding parameters: $v=8.5 \mathrm{~m} / \mathrm{min}, \quad \alpha=0^{\circ}, d=1.0 \mathrm{~mm}, f=0 \mathrm{~mm}$; $\mathrm{M}$-martensite, $\mathrm{B}$ - bainite, RA-retained austenite
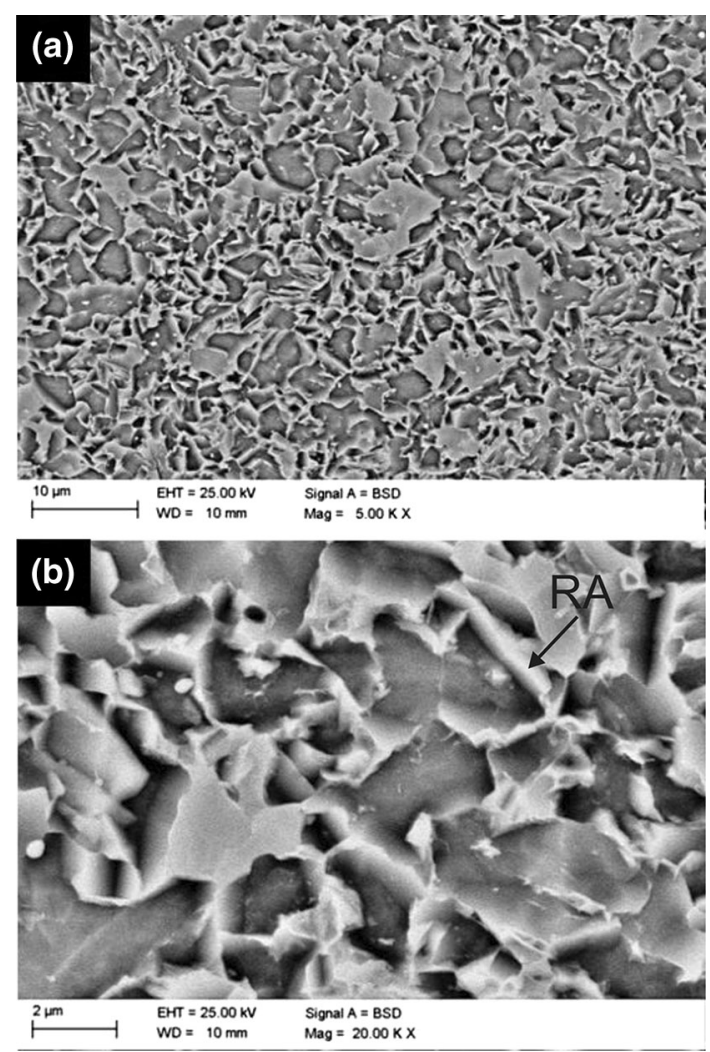

Fig. 14 Inter-critical HAZ of the DP steel at: (a) $\times 5 \mathrm{k}$ magnification; (b) $\times 20 \mathrm{k}$ magnification; welding parameters: $v=8.5 \mathrm{~m} / \mathrm{min}$, $\alpha=0^{\circ}, d=1.0 \mathrm{~mm}, f=0 \mathrm{~mm}$

fusion zone amounted to 430 HV5. The joints were characterized by the significant gradient of hardness. In the narrow fusion zone, the difference between two extreme values amounted to $15 \mathrm{HV} 5$, whereas in the heat-affected zone the hardness was lower by 75-100 HV5. In contrast to the HSLA steel, where an increase in the distance from the weld center was accompanied by a decrease in hardness (Ref 1,11$)$, the extreme measurement points of the HAZ in the DP steel revealed lower hardness than that observed in the base material. This phenomenon can be attributed to martensite tempering, leading to the formation of the soft zone $(\operatorname{Ref} 2,7,11)$. The
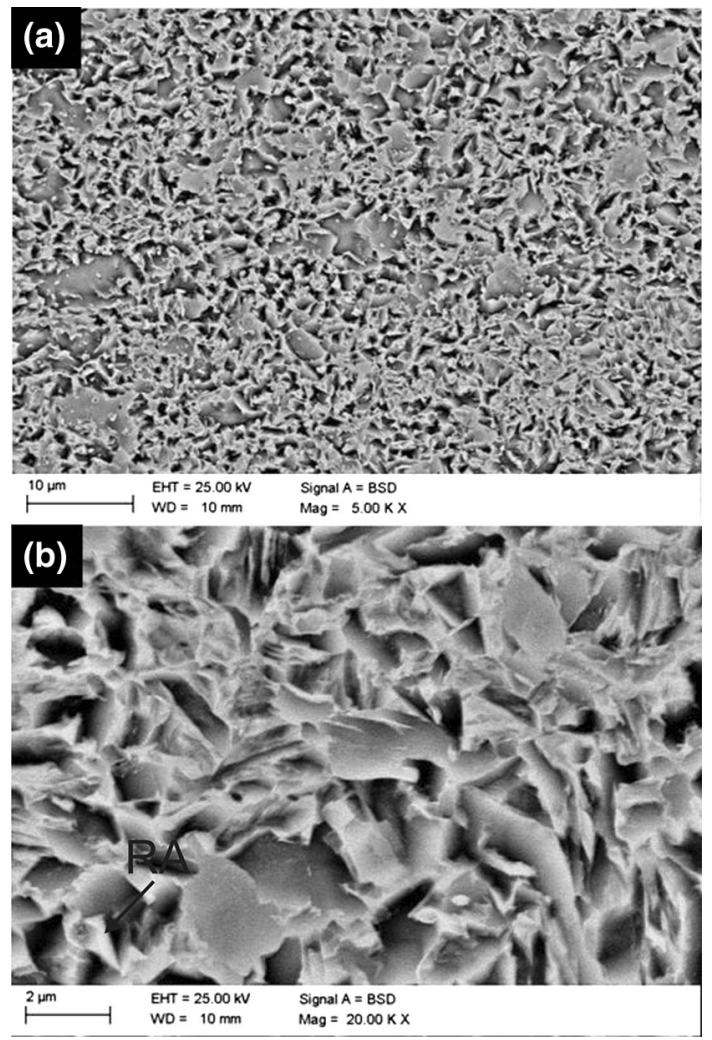

Fig. 15 Inter-critical HAZ of the HSLA steel at: (a) $\times 5 \mathrm{k}$ magnification; (b) $\times 20 \mathrm{k}$ magnification; welding parameters: $v=8.5 \mathrm{~m} / \mathrm{min}$, $\alpha=0^{\circ}, d=1.0 \mathrm{~mm}, f=0 \mathrm{~mm}$

lowest hardness value in the soft zone amounted to 250 HV5, i.e., by 15-20 HV5 less than that of the base material.

The joints subjected to twin-spot laser beam welding in the tandem mode (Fig. 16) were wider than those obtained during single-spot laser beam welding. This larger width was caused by the reduced welding rate, necessary to meet the criterion of penetration. As a result, the linear energy of welding increased, which in turn led to the lower hardness of the joint (max. 415 HV5). It should be noted that in the DP steel, the lowest hardness of the soft zone amounted to 237 HV5. The difference between the hardness of the base material and that of the tempered material increased by approximately 30 HV5. In turn, the width of the soft zone did not undergo visible changes. This phenomenon for single-spot laser beam welding has been discussed by Xia et al. (Ref 2). Twin-spot laser beam welding in the tandem mode was connected with an overall decrease in the hardness of the sheet made of the HSLA steel over the entire measured width. This decrease was caused by the significantly longer time (in comparison with single-spot beam welding) when the temperature affected mainly the sheet made of the HSLA steel (as it was placed on the sheet made of steel DP).

The smallest difference between the hardness of BM and that of the tempered martensite zone was present in the joints welded using the twin-spot laser beam $\left(\alpha=90^{\circ}\right)$ (Fig. 17) and amounted to 13-14 HV5. The positioning of the beams at an angle of $90^{\circ}$ resulted in the formation of the widest welds and the greatest uniformity of hardness of the fusion zone and base material. Moreover, the lowest hardness of the fusion zone for DP and HSLA, i.e., 409 HV5 and 376 HV5, respectively, was obtained. Similar to welding in the tandem mode, the hardness 


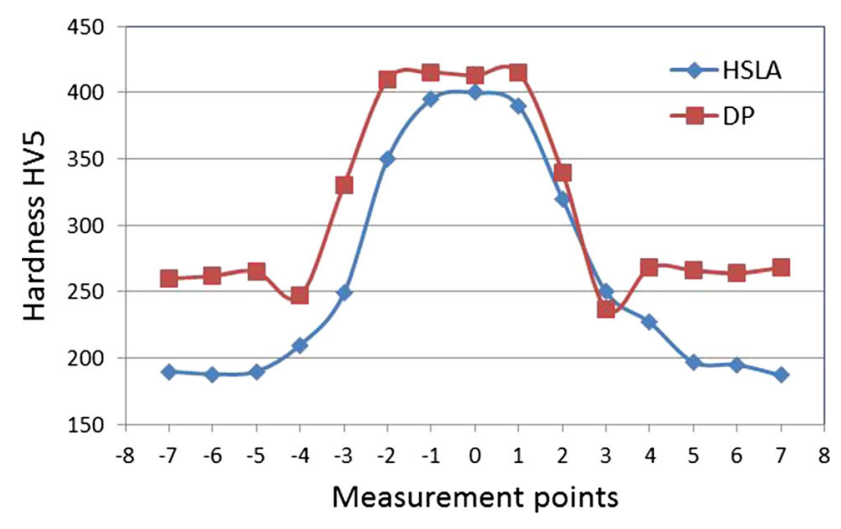

Fig. 16 Hardness measured at the half of the sheet thickness on the cross section of the joints made using the dual-beam technique, $\alpha=0^{\circ}$

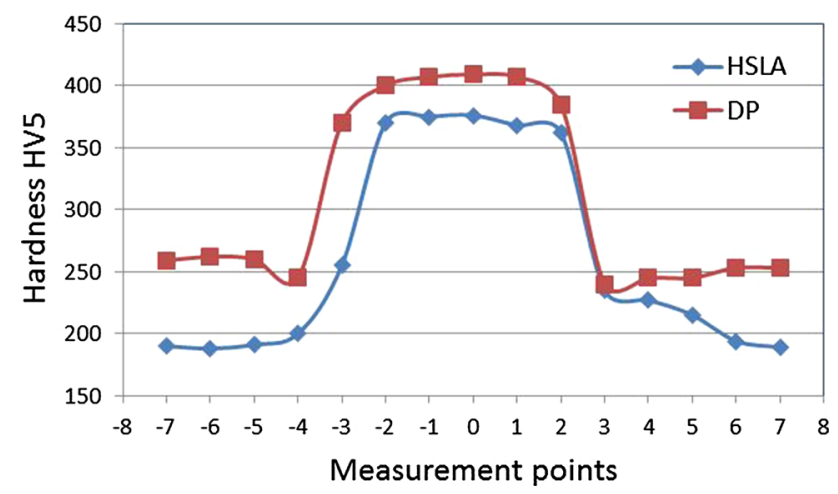

Fig. 17 Hardness measured at the half of the sheet thickness on the cross section of the joints made using the dual-beam technique, $\alpha=90^{\circ}$

of the base material test area decreased. After twin-spot laser beam welding, the asymmetry of hardness on the cross section was revealed. The reason for this asymmetry could be the heterogeneous distribution of laser beam power density (Ref 27).

Figure 18 presents data concerning the characteristics related to fusion curves in the primary points of the joints. The arrangement of the points in a horizontal line indicates the fusion line parallelism, which in turn is directly connected with the equal width of the face, joint and the root. The greatest width of the joint (over $1.4 \mathrm{~mm}$ ) and the greatest fusion line parallelism were obtained for twin-spot laser beam welding at an angle of $90^{\circ}$. Single-spot and twin-spot laser beam welding curves had inverse characteristics (in relation to each other). The smallest width of the joint was obtained during twin-spot beam welding in the tandem mode, although both the face and root widths were wider than those when the single-spot laser beam was used. Taking into consideration the fact that the use of the tandem mode entails a decrease in a welding rate and an additional decrease in hardness in the soft zone, it should be stated that single-spot laser beam welding is more favorable as regards the parameters used. However, unlike twin-spot welding at an angle of $90^{\circ}$, single-spot laser beam welding leads to the nonlinear transfer of stresses by the joint.

It is remarkable that in case of HSLA steel there is no soft zone in the HAZ. Since there is no martensite in the base

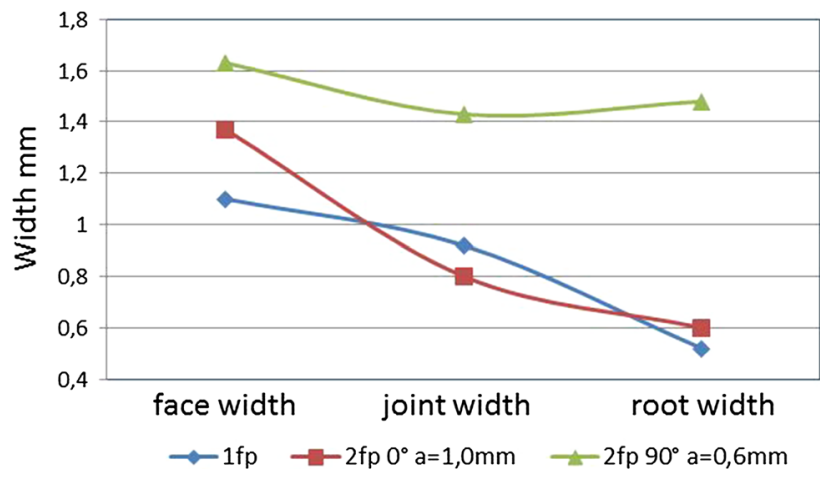

Fig. 18 Dimensions of the joints in the characteristic points of the cross section

microstructure of HSLA, it cannot be tempered and hence softened. Indeed, there is a significant growth of hardness in FZ and around it. This happens not only because of the high cooling rate, since the carbon content is low what does not allow to obtain very hard martensite. Rossini et al. (Ref 23) welded different types of advanced high-strength steels for automotive industry. In every case, the soft zone was observed, as in this study for the DP steel. A different behavior was observed by Zhu and Xuan (Ref 24). In the FZ hardness was very similar to BM and there was no soft zone in the HAZ. Moreover, the hardness increased to the peak point. The differences are caused by the $\delta$-ferrite in the FZ which forms right after welding, because of the high $\mathrm{Cr}$ content.

The beneficial reduction in hardness after applying the twinspot welding resulted in similar results to that reported by Zhu and Xuan after applying the post-weld heat treatment (Ref 29, 30). The difference between the highest hardness of the HAZ and BM was only about $20 \%$ leading to a relatively smooth joint hardness profile.

\section{Conclusions}

The applied parameters of laser welding involving the use of the beam split into two components enabled the obtainment of high-quality joints made of HSLA and DP steels. Dissimilar chemical compositions of the steels did not adversely affect the quality of the joints. The primary structural component of the fusion zone and heat-affected zone was lath martensite, indicating a high cooling rate, regardless of beam positioning. There were films of retained austenite and martensite-austenite blocks between martensite laths and martensite packets. The principal microstructural differences were observed in the intercritical heat-affected zone. In the HSLA steel, the mixture of fine-grained ferrite and martensitic-bainitic areas was identified. In case of the DP steel, characterized by greater hardenability, the microstructure was less fine-grained and contained martensite islands and retained austenite grains. The heat-affected zone and the fusion zone did not reveal significant tempering effects caused by the second beam. The effect of the interference of the beams was obtained, although a slight decrease in hardness, if compared to single-spot beam welding, was observed. Further research should focus on an increase in the distance between the focuses larger than $1 \mathrm{~mm}$ and different power distributions of the laser spots. 
In the DP steel, the zone of low-strength tempered martensite was formed between the base material and the HAZ. This phenomenon can be partially prevented by positioning the beams at an angle of $90^{\circ}$. Moreover, such a welding mode enables obtaining the widest overlap joint and reduces hardness both of the fusion zone and the HAZ by approximately $10 \%$. In turn, twin-spot welding in the tandem mode is more efficient and makes it possible to reduce hardness by approximately $5 \%$ in comparison with that obtained during single-spot laser beam welding.

\section{Open Access}

This article is distributed under the terms of the Creative Commons Attribution 4.0 International License (http://crea tivecommons.org/licenses/by/4.0/), which permits unrestricted use, distribution, and reproduction in any medium, provided you give appropriate credit to the original author(s) and the source, provide a link to the Creative Commons license, and indicate if changes were made.

\section{References}

1. A. Algahtani and E.R.I. Mahmoud, Effect of Fiber YAG Laser Parameters on the Microstructural and Mechanical Properties of High Strength Low-Alloy Steel, Int. J. Mater. Eng., 2015, 5, p 113-120

2. M. Xia, N. Sreenivasan, S. Lawson, Y. Zhou, and Z. Tian, A Comparative Study of Formability of Diode Laser Welds in DP980 and HSLA Steels, J. Eng. Mater. Technol. Trans. ASME, 2007, 129, p 446-452

3. Z. Gronostajski, A. Niechajowicz, and S. Polak, Prospects for the Use of New-Generation Steels of the AHSS Type for Collision Energy Absorbing Components, Arch. Metall. Mater., 2010, 55, p 221-230

4. M.S. Weglowski, K. Kwiecinski, K. Krasnowski, and R. Jachym, Characteristic of Nd:YAG Laser Welded Joints of Dual Phase Steel, Arch. Civ. Mater. Eng., 2009, 9, p 85-97

5. J. Gorka, Study of Structural Changes in S700MC Steel Thermomechanically Treated Under the Influence of Simulated Welding Thermal Cycles, Indian J. Eng. Mater. S., 2015, 22, p 497-502

6. L. Kucerova, H. Jirkova, and B. Masek, The Effect of Alloying on Mechanical Properties of Advanced High Strength Steels, Arch. Metall. Mater., 2014, 59, p 1189-1192

7. N. Farabi, D.L. Chen, and Y. Zhou, Fatigue Properties of Laser Welded Dual-Phase Steel Joints, Proc. Eng., 2010, 2, p 835-843

8. M. Opiela, Thermodynamic Analysis of the Precipitation of Carbonitrides in Microalloyed Steels, Mater. Tehnol., 2015, 49, p 395-401

9. A. Grajcar, K. Radwanski, and H. Krzton, Microstructural Analysis of a Thermomechanically Processed Si-Al TRIP Steel Characterized by EBSD and X-ray Techniques, Solid State Phenom., 2013, 203-204, p 34-37

10. A. Grajcar, M. Rozanski, S. Stano, and A. Kowalski, Microstructure Characterization of Laser-Welded Nb-Microalloyed Silicon-Aluminum TRIP Steel, J. Mater. Eng. Perform., 2014, 23, p 3400-3406

11. D.C. Saha, D. Westerbaan, S.S. Nayak, E. Biro, A.P. Gerlich, and Y. Zhou, Microstructure-Properties Correlation in Fiber Laser Welding of
Dual-Phase and HSLA Steels, Mater. Sci. Eng. A, 2014, 607, p 445453

12. K. Radwanski, A. Wrozyna, and R. Kuziak, Role of the Advanced Microstructures Characterization in Modeling of Mechanical Properties of AHSS Steels, Mater. Sci. Eng. A, 2015, 639, p 567-574

13. K. Radwanski, Structural Characterization of Low-Carbon Multiphase Steels Merging Advanced Research Methods with Light Optical Microscopy, Arch. Civ. Mech. Eng., 2016, 16, p 282-293

14. M. Pietrzyk, J. Kusiak, R. Kuziak, L. Madej, D. Szeliga, and R. Golob, Conventional and Multiscale Modeling of Microstructure Evolution During Laminar Cooling of DP Steel Strips, Metall. Mater. Trans. A, 2014, 45, p 5835-5851

15. D. Janicki, Disc Laser Welding of Armor Steel, Arch. Metall. Mater., 2014, 59, p 1641-1646

16. A. Lisiecki, Welding of Thermomechanically Rolled Fine-Grain Steel by Different Types of Lasers, Arch. Metall. Mater., 2014, 59, p 16251631

17. A. Grajcar and $\mathrm{S}$. Lesz, Influence of $\mathrm{Nb}$ Microaddition on a Microstructure of Low-Alloyed Steels with Increased Manganese Content, Mater. Sci. Forum, 2012, 706-709, p 2124-2129

18. J. Senkara, Contemporary Car Body Steels for Automotive Industry and Technological Guidelines of Their Pressure Welding, Weld. Int., 2013, 3, p 184-189

19. S. Pang, W. Chen, J. Zhuo, and D. Liao, Self-Consistent Modeling of Keyhole and Weld Pool Dynamics in Tandem Dual Beam Laser Welding of Aluminum Alloy, J. Mater. Proc. Technol., 2015, 217, p 131-143

20. S. Yan, Z. Hong, T. Watanabe, and T. Jingguo, CW/PW Dual-Beam YAG Laser Welding of Steel/Aluminum Alloy Sheets, Opt. Laser. Eng., 2010, 48, p 732-736

21. J. Milberg and A. Trautmann, Defect-Free Joining of Zinc-Coated Steels by Bifocal Hybrid Laser Welding, Prod. Eng. Res. Dev., 2009, 3, p 9-15

22. E. Capello, P. Chiarello, E. Piccione, and B. Previtali, Analysis of High Power $\mathrm{CO}_{2}$ Dual Beam Laser Welding, Advanced Manufacturing System and Technology, E. Kulianic, Ed., Springer, Berlin, 2002, p 473-480

23. M. Rossini, P.R. Spena, L. Cortese, P. Matteis, and D. Firrao, Investigation on Dissimilar Laser Welding of Advanced High Strength Steel Sheets for the Automotive Industry, Mater. Sci. Eng. A, 2015, 628, p 288-296

24. M.L. Zhu and F.Z. Xuan, Effects of Temperature on Tensile and Impact Behavior of Dissimilar Welds of Rotor Steels, Mater. Des., 2010, 31, p 3346-3352

25. C. Yuce, M. Tutar, F. Karpat, and N. Yavuz, The Optimization of Process Parameters and Microstructural Characterization of Fiber Laser Welded Dissimilar HSLA and MART Steel Joints, Metals, 2016, doi: $10.3390 /$ met6100245

26. https://www.ssab.com/products/brands/docol/products

27. S. Stano, A. Grajcar, Z. Wilk, M. Rozanski, P. Matter, and M. Morawiec, Microstructural Aspects of Twin-Spot Laser Welding of DP-HSLA Steel Sheet Joints, Arch. Metall. Mater., 2016, 61, p 731-740

28. J. Gorka, Weldability of Thermomechanically Treated Steels Having a High Yield Point, Arch. Metall. Mater., 2015, 60, p 469-475

29. M.L. Zhu and F.Z. Xuan, Effect of Microstructure on Strain Hardening and Strength Distributions Along a $\mathrm{Cr}-\mathrm{Ni}-\mathrm{Mo}-\mathrm{V}$ Steel Welded Joint, Mater. Des., 2015, 65, p 707-715

30. M.L. Zhu and F.Z. Xuan, Correlation Between Microstructure, Hardness and Strength in HAZ of Dissimilar Welds of Rotor Steels, Mater. Sci. Eng. A, 2010, 527, p 4035-4042 